\title{
The Effects of Smartphone on Students' Learning at National Dong Hwa University
}

\author{
Murni Sianturi*, Nurhayati \\ Department of Mathematics Education, Musamus University, Merauke, Indonesia \\ murni@unmus.ac.id,nurhayati_fkip@unmus.ac.id
}

\begin{abstract}
This study aimed to examine whether students consider that their mobile phones are useful devices for academic learning. Moreover, it was to investigate whether students' opinion on their mobile devices are useful devices for academic learning have any differences based on students' gender, age, college and type of their mobile phone; and students' opinion regarding capabilities of all features of Smartphone have positive correlation for effect of Smartphone to students' learning. The participants were students of four colleges in National Dong Hwa University. The effectiveness of Smartphone was measured by questionnaire consisted students' opinion on using their Smartphone in learning. Based on the findings of this study, students consider that their mobile phones were useful devices for academic learning, and provided positive impact in students' learning. However, students considered that their mobile phones were useful devices for academic learning did not depend on their gender, age, college, or type of their Smartphone. Capabilities of all features of Smartphone had positive correlation for effect of Smartphone to their learning.
\end{abstract}

Keywords: Smartphone, students' learning, features of Smartphone

\section{Introduction}

In recent decades, smartphone has become a main necessity. Even, for many people in developing countries it offers the only means of sending long distance messages particularly when their children are in the school. Nowadays, students have dependence of hand phone. Coupled with the times, the features and applications are always up to date make it would be very strange if students do not have a mobile phone. Features and applications of this phone are extremely diverse. Benefits are provided by other tools could be found in this tool, ranging from SMS and MMS, calculator, alarm clock and calendar, camera, games, computer applications, video and voice recording, music and video player, instant messages, email access, GPS (Global Positioning System), and internet access. In one tool, we could enjoy many benefits. Taiwan as one of wealth countries, recorded that about one-third of the population is smartphone or tablet computer users (Taipei Times, 2012). Amongst Asia-Pacific countries, Taiwan was number one for smartphone dependency, which eighty-one out of Taiwan's smartphone users do not leave home without their devices (Want China Times, 2014). Even more, the smartphone no longer only a tool for communication but a necessary instrument of work life, individuals' social, entertainment. It was growing rapidly nationwide. It indicated enable students in learning as well. Thornton \& Houser's findings (Thornton \& Houser, 2005) concurred in as much as students agreed that applying of smartphone capabilities assists them to achieve educational matters. Ransford (2009) investigated of about 300 college students found that ninety-nine percent of students have a mobile communication.

Which a twenty seven percent of own smartphone as compared to the national average of nineteen percent for working adults, and have a mobile communications device. Roughly, ninety-four percent of eighteen to thirty-four year-olds sent or received text messages and sixty-three percent of this age group accessed the internet by using their phone (Zickuhr, 2011). However, it is necessary to consider some other consequences of usage of smartphone. Learning has become more individualized and learner-centered. Applying the new digital technologies increasingly personalized. Most of students enjoy their own world while using the Smartphone. Universities allow students to bring mobile phone. Some schools are now providing pupils with Personal Digital Assistants and tablet computers. Sharples, Taylor, \& Vavoula (2010) have investigated that in a parallel development to the spread of personal technology since the early 1980s, schools, colleges and universities have experimented with handheld technology for learning, including classroom response systems, data probes, and handheld writing tools. Personal mobile technologies for learning become more widespread. McFarlane, Triggs, \& Yee (2008) started to show evidence of the value of incorporating mobile devices in teaching and learning. Yang's finding (2012) showed that most students at college of engineering at National Formosa University agreed that their motivation for English learning enhanced and most of them 
had positive attitudes towards m learning. No doubt if it would have same effects with students at the National Dong Hwa University.

There many students have smartphone carrying new advanced on their daily schedule. Thus, firstly this research considered students' opinion on smartphone as useful devices for academic learning. Secondly, it investigated whether there any different opinion on which state that Smartphone is useful devices for academic learning based on students' gender, age, college, and type of their Smartphone. Thirdly, it determined whether students regard those capabilities of all features of Smartphone have positive correlation for effect of Smartphone to students' learning.

\section{Literature Review}

Functional Capabilities of Smartphone: This present, Smartphone has popular and highly desirable. Certainly, the practicality and comfort of the smartphone becomes the primary reason that Smartphone sales in the world market increased rapidly. However, the consideration of the users is the feature of a Smartphone is very useful and diverse. With these features, the users are able to browse some applications they like. Zhou, Zhou, Jiang, \& Ning (2012) have stated that in the smartphone, there are approximately 200, 000 features. However, in our study only limits to several features normally used in general society. As these features are calculator, SMS and MMS, internet access, alarm clock and calendar, camera, email access, educational games, computer application, video and voice recording, GPS and maps, music and video player, and instant messages.

The Impact of Mobile Phones in Learning: At least there are three impacts of smartphone in learning. Firstly is easy of finding information through the internet. The present of wireless mobile technology recently has given easiness in learning (Kuznekoff \& Titsworth, 2013). Since, internet connection anywhere and anytime, every student obtains some literacy rapidly (Etoekleous \& Ktoridou, 2009) and gathers some information for inquiry-based learning in outdoor learning activities (Vavoula, Sharples, Rudman, Meek, \& Lonsdale, 2009). Smartphone become portability device and own a continuously available Web-enabled phone (Thornton \& Houser, 2005). Secondly is the use of a smartphone as mobile learning (m learning), Sophistication of technology has more or less been encouraging teachers to consider a modern learning. One of the most talked about is m learning. The educational use of the mobile devices was submitted to as $\mathrm{m}$ learning with the focus on enlarging and facilitating the reach of the teaching and learning, such as the knowledge construction, the information collection and exchange, the collaborative learning (Elias, 2011). M learning defined as learning across multiple contexts, through social and content interactions, using personal electronic devices (Crompton, 2013). Thus, by using mobile devices, students can learn portably. M learning concerns on students' movement portably.

In addition, the teachers get more mobility, creation and innovation in material of learning through a new way in m learning with uses Smartphone with special software such as AHG Cloud Note (El-Hussein \& Cronje, 2010). There are many smartphone's features for creating learning that aids in informal learning. Mobile learning seems like other forms of e learning, that it is also collaborative. M learning also replaces books and notes with small devices by filling suitable learning materials. Beside it, students can operate their mobile devices for a more effective and entertaining experience, especially they get boring while learning. Thirdly is enhancing students' motivation, attitude and self-efficacy. The results echoed the previous study in that the mobile learning project can increase students' learning participations in the learning tasks (Attewell, 2005; Yang, 2012). As well, this paper judged students are enthusiast enough to read the assigned texts, post questions, read and provide feedback to peers by using mobile devices. Yang finding (Yang, 2012) stated students demonstrated positive attitudes toward m learning. The indication was students argued that mlearning help them to find more information and supported learning contents. Frequently, after the learners shared their notion in the online discussion, they look forward messages from peers via mobile devices. This study offered additional support in that the students' computer self-efficacy and attitudes were core factors, which affected the success of mobile learning. 


\section{Research Methods}

Research Design: The research methodology of the study was quantitative research method to properly analyze and give a comprehensible description of the study. The procedures were distributing questionnaire to participants. (Hopkins, 2000) stated quantitative research is a study about involves quantifying relations between variables and expressing the relations among variables by analysis statistics such as difference between means and variances, correlations, and relative frequencies. It means that the student consider that their Smartphone are useful devices for academic learning.

Participants: Sample of the study was randomly determined. The participants were students of Humanities and Social Science, Education, Art, and Management departments. The number of students was fifty-four participants with study levels were undergraduate and graduate. Table 1 provides distribution of sample size, which involves college, gender, and age.

Table 1: Demography of Participants

\begin{tabular}{llcccccccc}
\hline Criteria & $\begin{array}{l}\text { Humanities } \\
\text { and Social } \\
\text { Science }\end{array}$ & Education & Arts & Management & Female & Male & $\mathbf{1 8 - 2 0}$ & $\begin{array}{l}\mathbf{2 1 -} \\
\mathbf{2 3}\end{array}$ & $\geq \mathbf{2 4}$ \\
\hline $\begin{array}{l}\text { College } \\
\begin{array}{l}\text { Gender } \\
\text { Age (year(s)) }\end{array}\end{array}$ & 24 & 6 & 6 & 18 & & & & & \\
\hline
\end{tabular}

Questionnaire: This study used questionnaire was adapted and modified based on existing previous study (Mokoena, 2011). The study gathered all information from the responses of participants of the study with a structured questionnaire. There are two parts of items. First part related to participants' information such as college, gender and age, and second part is questions regarding student's opinion toward usage of smartphone to enhance students' learning at university. Each participant was given the same questionnaire consists the same questions. The participants gave responses to each question. The contents of the second section consist of the student opinions and experience. The responses to these questions were designed as closed-end questions. The questions are as follows:

Item 1: Smartphones are useful tools for student learning.

Item 2: Smartphones are as well as PDAs in the classroom environment.

Item 3: Smartphones are distracting for students during lectures/learning.

Item 4: Smartphones access to the internet enriches students' learning experience.

Item 5: Smartphones technology has brought about advancements in students' learning setting.

Data Analysis Techniques: The collected data, analyze in descriptive statistics by using the Statistical Programmed for Social Sciences (SPSS) package. The data are analyzed using descriptive statistics, one sample mean test, independent t-test, and ANOVA for the study findings and results. The hypothesis of the study is as follows:

$\mathrm{H}_{0} \quad$ : Students consider that their Smartphone are not useful devices for academic learning $: \mu \leq 3$

$\mathrm{H}_{1} \quad$ : Students consider that their Smartphone are useful devices for academic learning. $: \mu>3$

By descriptive analysis specific was to determine whether the percentage of students' opinion "agree" and strongly agree were at $50 \%$. The following table is an analysis of descriptive results of section B. Based on the five questions of section B would test the hypothesis for each question by using SPSS of descriptive and one sample mean t-test. The specific was to determine whether mean $\leq 3$ or mean $>3$. Further hypotheses were to examine whether there any different based on students' gender, age, college, and type of their Smartphone on their opinion, which state that Smartphone is useful devices for academic learning for each statement in section B. Thus, there are four hypotheses needed as follow. 


\section{Gender}

$\mathrm{H}_{0} \quad$ : There is no different significantly between female and male on the students' opinion of statement B $\mu_{1}=\mu_{2}$

$\mathrm{H}_{1} \quad$ : There is different significantly between female and male on the students' opinion of statement B Age of years

$$
: \mu_{1} \neq \mu_{2}
$$

$\mathrm{H}_{0} \quad$ : There is no different significantly amounts each age on the students' opinion of statement B $: \mu_{1}=\mu_{2}=\cdots=\mu_{5}$

$\mathrm{H}_{1} \quad$ : There is different significantly amounts each age on the students' opinion of statement B : At least one different

College

$\mathrm{H}_{0} \quad$ : There is no different significantly amounts each college on the students' opinion of statement B $: \mu_{1}=\mu_{2}=\cdots=\mu_{5}$

$\mathrm{H}_{1} \quad$ : There is different significantly amounts each college on the students' opinion of statement B : At least one different

\section{Results and Discussion}

Results: Descriptive Result Analysis

Table 2: Descriptive Analysis and One Sample T-Test of Result for Section B

\begin{tabular}{lrrrr}
\hline Statements & $\mathbf{3}$ & $\boldsymbol{\mu}$ & One Sample T-test & Sig. $^{*}$ \\
\hline Item 1 & 9 & $\mathbf{3}$ & \multicolumn{1}{c}{ T } & 0.000 \\
Item 2 & 28 & 26 & 11.406 & 0.000 \\
Item 3 & 9 & 45 & 1.724 & 0.000 \\
Item 4 & 11 & 43 & 11.543 & 0.000 \\
Item 5 & 16 & 35 & 7.694 & 0.000 \\
Total & & & & \\
\hline$*$
\end{tabular}

*: $95 \%$ confident interval

Table 2 describes that the p-value for the entire hypothesis were 0.000 . It means that p-value was less than $\alpha .05$. Therefore, we could conclude that mean significantly was greater 3 . Then, we could also conclude that more than $50 \%$ students considered "agree" even "strongly agree" for all question in the section B, except statement Smartphones are as good as PDAs in the classroom environment. It occurred because, not all implied in their classroom, so that some students give neutral for this statement. Even though according to prior study, Mokoena (2011), stated that mobile phones gave impact to students' learning activities. The conclusion of the analysis of the null hypothesis rejected. By using mobile phones can give positive impact to the students. To analysis hypotheses of gender used independent sample t-test. The result of analysis described in below table.

Table 3: Analysis Result Gender for Each Statement of Section B

\begin{tabular}{lrc}
\hline Statements & \multicolumn{1}{c}{ T } & Sig. $^{*}$ \\
\hline Item 1 & 0.000 & 1.000 \\
Item 2 & -1.057 & 0.295 \\
Item 3 & -1.652 & 0.105 \\
Item 4 & -0.197 & 0.845 \\
Item 5 & -1.619 & 0.112 \\
\hline
\end{tabular}

*: $95 \%$ confident interval

According to $\mathrm{p}$-value from table above, it described that the $\mathrm{p}$-value for the entire hypothesis were greater than $\alpha_{.05}$. Therefore, we could conclude that there is no different significantly between female and male on the 
students' opinion of statement B or gender doesn't give effects significantly on each student' opinion of statements B. To analysis hypotheses of age used ANOVA. The result of analysis described in table 4.

Table 4: Analysis Result Age for Each Statement of Section B

\begin{tabular}{lrc}
\hline Statements & F & Sig. $^{*}$ \\
\hline Item 1 & 0.627 & 0.538 \\
Item 2 & 2.826 & 0.069 \\
Item 3 & 0.619 & 0.543 \\
Item 4 & 1.883 & 0.163 \\
Item 5 & 0.448 & 0.641 \\
\hline
\end{tabular}

*: $95 \%$ interval confidence

According to $\mathrm{p}$-value from table above, it described that the $\mathrm{p}$-value for the entire hypothesis were greater than $\alpha_{.05}$. Therefore, we could conclude that there is no different significantly amounts each age of students on the students' opinion of statement B or age doesn't give effects significantly on each student' opinion of statements B. Analysis hypotheses of age applied ANOVA. The result of analysis described as in following table.

Table 5: Analysis Result of College for Each Statement of Section B

\begin{tabular}{lrc}
\hline Statements & F & Sig. $^{*}$ \\
\hline Item 1 & 1.553 & 0.212 \\
Item 2 & 0.288 & 0.834 \\
Item 3 & 2.054 & 0.118 \\
Item 4 & 1.544 & 0.215 \\
Item 5 & 0.432 & 0.731 \\
\hline
\end{tabular}

*: $95 \%$ interval confidence

Based on p-value of table 5, it reveals the p-value for the entire hypotheses were greater than $\alpha_{.05}$. Therefore, we could conclude that there is no different significantly amount each age of students on the students' opinion of statement B or age doesn't give effects significantly on each student' opinion of statements B.

Discussion: Based on descriptive result, the finding's study is students consider that their smartphone are useful devices for academic learning. According to their opinion, they experience that their smartphone is useful devices to help their learning, as good as PDAs in the classroom environment, internet enriches students' learning experience, and Smartphone technology has brought about advancements in students' learning setting. However, some students have opinion that their Smartphones are not as good as PDAs in the classroom environment. It occurred because, not all implied in their classroom, so that some students give neutral opinion for this statement. Even though according to prior study, the Mokoena (2011), stated that mobile phones gave impact to students' learning activities. Moreover, the study viewed that there is not any significantly different amounts students' gender, age, college, and type of their Smartphone on their opinions, which state that Smartphone is useful devices for academic learning.

These show the students consider that their mobile phones are useful devices for academic learning does not depend on their gender, age, college, or type of their Smartphone. However, toward considering of internet enriches students' learning experience, there is significantly different between Samsung Smartphone and other Smartphone. Since comparison between samples that have Samsung Smartphone disproportionate to other Smartphone, this be deduced in detail. Based on previous study, Mokoena, (2011) also stated that there is no association between gender and type of their mobile phone toward their opinion that their mobile phones are useful devices for academic learning. Additionally, all features of Smartphone have positive correlation for impact of Smartphone to their learning. The students regard Smartphone's features as contributing significantly to help the student in learning. 


\section{Conclusion and Suggestions}

Conclusion: Based on the results of research and discussion, some conclusions such as students consider that their mobile phones are useful devices for academic learning. It means that using smartphone result in positive impact in students' learning. The students consider that their mobile phones are useful devices for academic learning does not depend on their gender, age, college, or type of their smartphone. Capabilities of all features of smartphone have positive correlation for effect of Smartphone to their learning.

Suggestions: Based on conclusion of the present study, the finding of study supports students to use Smartphone to help their learning activities. The students can use smartphone anytime and anywhere. For further researcher, the findings of the study will become considering conducting next related study. The further researcher can examine whether fix application in of Smartphone is able to implementation in classroom. Moreover, the study will give some judgment to teacher to design m learning at school.

\section{References}

Attewell, J. (2005, December 25). From research and development to mobile learning: tools for education and training provider and their learners.

Crompton, H. (2013). A historical overview of mobile learning: Toward learner-centered education. In Berge, Z. L. \& Muilenburg, L. Y. Handbook of Mobile Learning (pp. 3-14). Florence, KY: Routledge.

El-Hussein, M. O. \& Cronje, J. C. (2010). Defining mobile learning in the higher education landscape. Educational Technology \& Society, 13(3), 12-21.

Elias, T. (2011). Universal instructional design principles for mobile learning. International Review of Research in Open and Distance Learning, 12(2), 143-156.

Etoekleous, N. \& Ktoridou, D. (2009, April 28). Investigating Mobile Devices Integration in Higher Education in Cyprus: Faculty Perspective. Frederick University Cyprus, School of Education, Nicosia, Cyprus and University of Nicosia, School of Business, Nicosia, Cyprus, 38-40.

Hopkins, W. G. (2000). Quantitative research design. Sportscience, 4(1), 12-21.

Kuznekoff, J. H. \& Titsworth, S. (2013). The impact of mobile phone usage on student learning, communication education, 62(3), 233-252.

McFarlane, Triggs, P. \& Yee, W. (2008). Mobile learning: Research findings.

Mokoena, S. (2011). Smartphones and regular cellular phones: assessing their impact on students' education at the university of zululand (main campus).

Ransford, M. (2009, March 25). Survey Finds Smart Phones Transforming mobile lifestyles of college students.

Sharples, M., Taylor, J. \& Vavoula, G. (2010). Medienbildung in neuen Kulturräumen, 87-99.

Taipei Times. (2012). One in three people use Smartphone, tablet computers. Taiwan: Taipei Times.

Thornton, P. \& Houser, C. (2005). Using mobile phones in English Education in Japan. Journal of Computer Assisted Learning, 21, 217-228.

Vavoula, G., Sharples, M., Rudman, P., Meek, J. \& Lonsdale, P. (2009). MyArtSpace: Design and evaluation of support for learning with multimedia phones between classrooms and museums. Computer and Education, 53(2), 286-299.

Want China Times. (2014). Taiwan No.1 for Smartphone dependency in Asia-Pacific: poll. China: Want China Times.

Yang, S. H. (2012). Exploring college students' attitudes and self-efficacy of mobile learning. The Turkish Online Journal of Educational Technology, 11(4), 1-7.

Zhou, W., Zhou, Y., Jiang, X. \& Ning, P. (2012). Detecting repackaged smartphone applications in third-party android marketplaces, North Carolina State University. CODASPY, 12, 317-326.

Zickuhr, K. (2011). Generations and gadgets. 